\title{
0 impacto dos acidentes e violências nos gastos da saúde
}

\section{Impact of accidents and violence on health costs}

Correspondência | Correspondence: Secretaria de Estado da Saúde de São Paulo Av. Dr. Arnaldo, $3511^{\circ}$ andar sala 135 01246-901 São Paulo, SP, Brasil

E-mail: agencia@saude.sp.gov.br

Texto de difusão técnico-científica da Secretaria de Estado da Saúde de São Paulo.

\author{
Grupo Técnico de Prevenção de Acidentes e Violências. Centro \\ de Vigilância Epidemiológica "Prof. Alexandre Vranjac". Coorde- \\ nadoria de Controle de Doenças. Secretaria de Estado da Saúde \\ de São Paulo
}

Nas últimas décadas, o Brasil experimentou mudanças no perfil epidemiológico dos agravos, tanto em relação às doenças infecciosas (com o surgimento de novos agentes patogênicos), como às não infecciosas. Os acidentes e violências (causas externas) têm determinado um importante impacto na saúde das populações de vários países do mundo. A comparação com outros países mostra que as taxas brasileiras são muito altas - terceiro lugar para os homicídios e quinto lugar para os acidentes de trânsito. Dada essa magnitude, cada vez mais os serviços de saúde precisam alocar profissionais e equipamentos para o atendimento à essas vítimas que, muitas vezes, exigem o cuidado de uma série de especialistas: neurocirurgiões, ortopedistas, cirurgiões de abdome e tórax, fisioterapeutas e outros.

As conseqüências dos acidentes e violências para o sistema de saúde e para a sociedade apontam a necessidade de aperfeiçoamento do sistema de informações de mortalidade e morbidade por causas externas, com vistas a subsidiar políticas públicas para a prevenção do problema e atendimento às vítimas. No Estado de São Paulo, há o Sistema de Vigilância Epidemiológica dos Acidentes e Violência, operado pelo Grupo Técnico de Prevenção de Acidentes e Violências (GTPAV), do Centro de Vigilância Epidemiológica "Prof. Alexandre Vranjac" (CVE) - órgão da Coordenadoria de Controle de Doenças, da Secretaria de Estado da Saúde (CCD/SES-SP). Esse Sistema está baseado em três prioridades: 1) o acompanhamento dos dados do Sistema de Informações de Mortalidade e Sistema de Informações Hospitalares; 2) o estabelecimento da Rede de Atendimento às Vítimas de Violência Sexual e 3) prevenção e notificação dos maus-tratos contra a criança e o adolescente.

No período de dois anos de existência do GTPAV al- guns avanços podem ser apontados: interlocutores instituídos nas 24 Diretorias Regionais de Saúde (DIR) do Estado; capacitações para análise dos dados; construção pactuada de indicadores; parcerias com outras instituições; recursos e pesquisas. Uma das tarefas mais valorizadas pelo Grupo é a disseminação de informações, pela publicação regular dos dados epidemiológicos do Estado.

Apesar da magnitude dos gastos envolvidos com os cuidados de atenção à saúde das vítimas de violência e dos custos econômicos decorrentes da perda de vida produtiva por morte, incapacidade ou prisão, são poucos os estudos no País para avaliar o impacto econômico decorrente dessas causas. Do ponto de vista conceitual, o custo econômico de uma doença ou agravo pode ser classificado em diretos e os indiretos. Os primeiros dizem respeito aos gastos com a atenção médica, propriamente dita, que incluem tratamento, exames complementares, internações e reabilitação. A esses podem ser somados os gastos do paciente com transporte para a realização do tratamento e dieta especial, entre outros (se houver necessidade de acompanhante nas consultas e tratamentos, esses gastos se tornam ainda maiores). Os custos indiretos referem-se à perda de dias de trabalho, menor produtividade gerada por limitações físicas e/ou psicológicas e os danos materiais que porventura ocorram, entre outros.

Existem, ainda, os custos de mensuração mais difícil, gerados pelo impacto social determinado por essas causas os quais podem ter reflexos no ambiente econômico. Segundo cálculos, o Brasil deixou de arrecadar US\$ 20 bilhões entre 1998 e 1999 com o turismo, em razão do impacto negativo da violência no País. Uma vez que se estima que cada US\$1,000 gastos por turistas geram de dois a três empregos, o pro- 


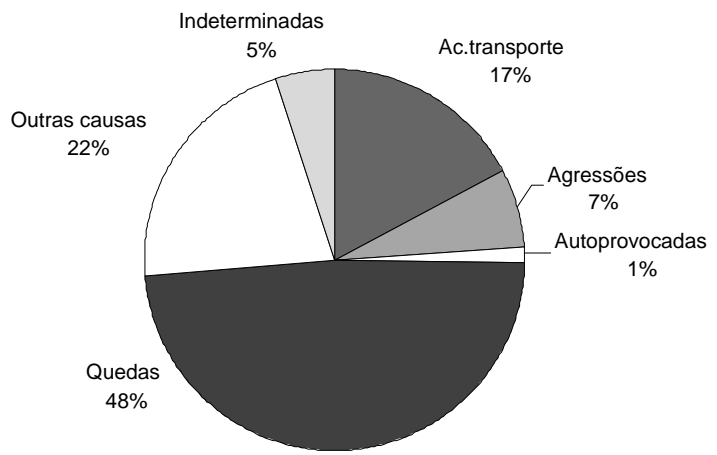

Fonte: Sistema de Informações Hospitalares/D atasus

Figura 1 - Distribuição das internações por causas externas. Estado de São Paulo, 2005.

blema do desemprego no Brasil, nas regiões turísticas, seria praticamente reduzido a zero se esse fluxo de visitantes fosse mantido.

Assim, foram coletados os dados para avaliar o impacto econômico das internações por causas externas realizadas no Sistema Único de Saúde (SUS) no Estado de São Paulo, em 2005.

O banco de dados utilizado foi o Sistema de Internações Hospitalares do Sistema Único de Saúde (SIH/SUS), construído com os dados que compõem a Autorização de Internação Hospitalar (AIH), documento obrigatório nas internações realizadas pelo SUS. Atualmente, esse banco contém os códigos relativos ao tipo de causa externa, além da natureza da lesão (acessíveis desde 1992). Esse banco é disponibilizado para a Secretaria da Saúde de São Paulo pela Fundação Sistema Estadual de Análise de Dados (Seade). Foram selecionados os casos classificados como diagnóstico principal ou no diagnóstico secundário constantes no Capítulo XIX e XX da CID-10. As categorias de causas externas analisadas foram as seguintes: acidentes de transporte (V01 a V99), quedas (W00 a W19), suicídios (X60 a X84), homicídios (X85 a Y09) e lesões de inten-

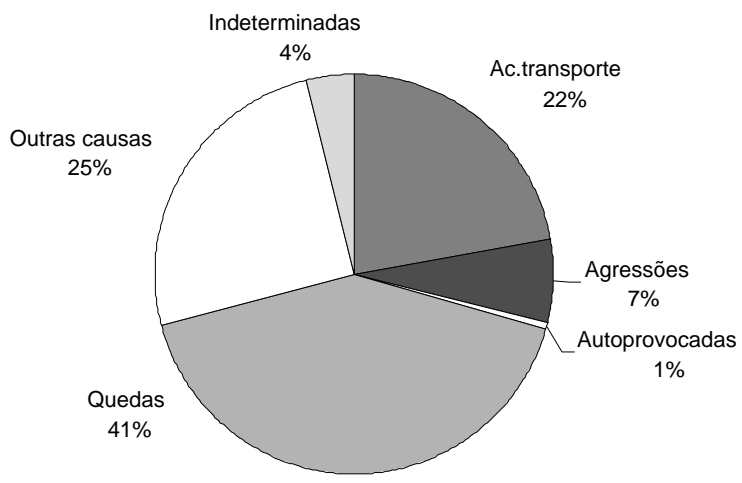

Fonte: Sistema de Informações Hospitalares/ Datasus

Figura 2 - Distribuição dos custos da morbidade hospitalar por causas externas. Estado de São Paulo, 2005. cionalidade indeterminada (Y10 a Y34). Para a análise do custo da internação foram selecionados os casos não somente por local de residência (usualmente utilizado, pois permite o cálculo de taxas), mas também por local de internação, para se obter o valor real do custo.

Foram realizadas análises por sexo e faixa etária. As taxas foram calculadas por 100.000 habitantes. Os dados populacionais para a construção dessas taxas foram baseados nos Censos de 1991 e 2000, disponibilizados no site do Datasus.

\section{Internações decorrentes de causas externas}

Os resultados a seguir dizem respeito ao universo das 195.009 internações decorrentes de causas externas da população residente do Estado de São Paulo, ocorridas no ano de 2005. A distribuição segundo o sexo mostrou que $69,4 \%$ dessas vítimas pertenciam ao sexo masculino ( 135.295 homens) e $29,6 \%$ do ao sexo feminino (59.710 mulheres).

A Figura 1 mostra as hospitalizações segundo os tipos de causas externas. Observa-se que as quedas lideraram essas causas, responsáveis por quase metade $(48,2 \%)$ do total. Em segundo lugar, encontram-se as demais causas $(21,5 \%)$, nas quais se destacam as complicações de procedimentos médicocirúrgicos, seqüelas de causas externas e queimaduras. Seguem-se os acidentes de transporte, que perfizeram $17,1 \%$ do total dessas causas. Vale ressaltar que a maior parte das vítimas de acidentes de transporte é de pedestres (32,2\% do total de internações por essa causa), seguidos dos motociclistas $(29,2 \%$ do total dessas internações). As agressões foram responsáveis por $6,9 \%$, e as lesões autoprovocadas por $1,3 \%$ das hospitalizações. Tal padrão é completamente diverso daquele verificado para a mortalidade, em que os homicídios preponderam.

\section{Custos das internações}

Quando foi analisado o total das internações do Estado segundo os capítulos da CID-10, observou-se forte impacto dos acidentes e violências nos custos hospitalares, uma vez que estas causas ocuparam o sexto lugar em número de internações, mas estiveram em terceiro lugar no valor total pago pelo SUS. Internações por essas causas consumiram $\mathrm{R} \$ 155.091 .524,39$ dos cofres públicos.

A Figura 2 apresenta os percentuais do valor total pago pelo SUS segundo os diferentes tipos de causas externas. Além de liderarem como causa de morbidade, as quedas lideram também os custos, mas em pro- 
porções um pouco menores $(41,0 \%)$. Já os acidentes de transporte representam $22,0 \%$ do custo total.

Embora representem quase o triplo do número de hospitalizações por acidentes de transporte, as quedas respondem por um gasto de 1,8 vezes maior que as internações por acidentes de transporte. Por outro lado, o custo médio das internações por acidente de transporte foi $52 \%$ maior que o custo médio de internações por queda. Por esses dados, pode-se inferir que as quedas oneram o SUS pela magnitude com que incidem na população, enquanto os acidentes de trânsito, embora motivem quase três vezes menos internações que as quedas, possuam um custo médio por internação mais elevado.

As agressões apresentaram um impacto equivalente em relação à morbidade e custo, isto é, 7\% da morbidade e 7\% do custo total do SUS com internações por causas externas. O custo médio de internações por agressões foi $25 \%$ menor que o custo médio de internações por acidentes de trânsito e $14 \%$ maior que as internações por queda. No entanto, em termos de custos globais, as internações por agressões representaram cerca de $1 / 6$ do custo das internações por quedas e 1/3 do custo das internações por acidentes de transporte. As lesões autoprovocadas, com um impacto semelhante em termos de morbidade e custo, tiveram o menor custo médio e global para o SUS em relação às outras causas descritas.

Na Tabela estão relacionados os valores pagos pelo SUS para internações hospitalares por causas externas no ranking dos dez municípios do Estado que tiveram os maiores gastos. Nessa tabela, são comparados os custos por local de internação e local de residência da vítima, uma vez que os municípios com mais recursos e/ou melhores equipamentos para atenção à saúde (tais como hospitais especializados no atendimento ao trauma) se constituem referência para pacientes de outros locais. Com exceção feita a Guarulhos, nos demais municípios os custos foram maiores quando classificados por local de internação do que por local de residência.

A diferença de gastos entre as duas classificações (por local de internação e por local de ocorrência) foi sempre maior que $\mathrm{R} \$ 1$ milhão, sendo que em São Paulo essa diferença foi de quase $\mathrm{R} \$ 12$ milhões, denotando, mais uma vez, a importância desse município para a cobertura das cidades com menor capacidade assistencial.

\section{Políticas de prevenção}

Entre as características particulares das causas externas estão a sua complexidade e abrangência. Dentro deste grupo estão reunidos diferentes tipos de agravos (acidentes de trânsito, violência doméstica, afogamentos, quedas, queimaduras, desastres naturais, violência sexual e abuso contra o idoso, entre outros) que, por terem gênese diversa, também demandam intervenções muito diferentes. Desta forma, é preciso estabelecer prioridades para a ação, o que geralmente não se constitui em tarefa simples.

Os resultados apresentados são relevantes, porque, ao apontar as causas de internações que representam maior custo para os cofres públicos, podem auxiliar na seleção de prioridades de intervenção. À luz dos conhecimentos atuais, a maioria das lesões pode ser prevenida. Em relação aos acidentes de trânsito, a utilização de cintos de segurança nos carros, melhor sinalização das vias e as campanhas educativas sobre a associação do consumo de álcool e risco aumentado de acidentes de trânsito (incentivo à direção responsável) se constituem em bons exemplos de medidas preventivas.

Em relação à importância das quedas como determinantes de internações, a literatura internacional indica que intervenções efetivas provocam impacto positivo na redução dos seus danos. Com o aumento da expectativa de vida, especial atenção deve ser dire-

Tabela - Municípios com maiores gastos hospitalares por causas externas, segundo local de internação e local de residência. Estado de São Paulo, 2005.

\begin{tabular}{lcc}
\hline Município & Local de internação & Local de residência \\
\hline São Paulo & $\mathrm{R} \$ 55.270 .183,72$ & $\mathrm{R} \$ 43.547 .556,46$ \\
Ribeirão Preto & $\mathrm{R} \$ 6.531 .038,16$ & $\mathrm{R} \$ 3.517 .932,10$ \\
S. José do Rio Preto & $\mathrm{R} \$ 6.292 .812,08$ & $\mathrm{R} \$ 3.043 .667,70$ \\
Campinas & $\mathrm{R} \$ 5.031 .219,74$ & $\mathrm{R} \$ 3.893 .655,96$ \\
Sorocaba & $\mathrm{R} \$ 4.713 .261,81$ & $\mathrm{R} \$ 2.339 .836,89$ \\
Santos & $\mathrm{R} \$ 4.138 .684,11$ & $\mathrm{R} \$ 2.542 .028,82$ \\
Mogi das Cruzes & $\mathrm{R} \$ 3.863 .710,15$ & $\mathrm{R} \$ 2.034 .110,35$ \\
Marília & $\mathrm{R} \$ 2.564 .435,60$ & $\mathrm{R} \$ 1.258 .692,47$ \\
Bauru & $\mathrm{R} \$ 2.429 .222,70$ & $\mathrm{R} \$ 1.365 .073,40$ \\
Catanduva & $\mathrm{R} \$ 2.419 .080,17$ & $\mathrm{R} \$ 912.616,81$ \\
Guarulhos & $\mathrm{R} \$ 2.315 .525,49$ & $\mathrm{R} \$ 4.213 .805,79$ \\
\hline Total do Estado & $\mathrm{R} \$ 157.582 .336,35$ & $\mathrm{R} \$ 155.091 .524,39$ \\
\hline
\end{tabular}

Fonte: Sistema Único de Saúde 
cionada para a população de 60 anos e mais, que é bastante suscetível a esse agravo. O declínio da função visual (iniciado, geralmente, já na quinta década de vida) e funções músculo-esqueléticas (tais como a perda da força muscular, agilidade e coordenação), podem ser compensados com intervenções oftalmológicas, audiológicas e indicação de exercícios físicos para melhorar a força e a flexibilidade muscular. Para tanto, torna-se importante o diagnóstico precoce dessas condições por meio de exame de saúde voltado para a identificação de fatores de risco individuais para causas externas, tais como acuidade auditiva e visual, osteoporose, dificuldades cognitivas, emocionais e mobilidade.

Os serviços de atendimento pré-hospitalar também devem merecer atenção especial, podendo ter impacto na redução da letalidade dessas causas. Entretanto, mesmo um bom cuidado na fase pré-hospitalar não consegue reverter um quadro extremamente grave. A chave da redução da mortalidade ainda é a prevenção primária, uma vez que muitos pacientes não conseguem ser beneficiados com os avanços do cuidado moderno.

Esclarece-se que não foram incluídos os dados de atendimentos de emergência que, nos casos de acidentes e violências, podem representar um volume considerável de recursos. Também os valores reembolsados pelo SUS podem, por vezes, não estar refletindo os custos reais dos procedimentos para determinados serviços. Da mesma forma, o banco de morbidade não inclui os casos atendidos em hospitais não conveniados com o Sistema Único de Saúde.

Com relação à qualidade da informação (o que deve acontecer também com os outros agravos), não foi possível identificar, por exemplo, os diferentes tipos de quedas e os cenários onde elas ocorrem, aspectos importantes para a orientação das políticas de prevenção.

A prevenção das causas externas não é assunto somente relevante para a saúde pública, mas para outras instituições como a Segurança Pública, Educação e Promoção Social, além de ser do interesse de todos os cidadãos. Os profissionais de saúde podem desempenhar um importante papel no diagnóstico de determinadas condições que se configuram em fatores de risco, bem como no tratamento e orientação de pacientes e familiares. Esse profissional encontra-se, muitas vezes, numa posição privilegiada para ajudar aqueles que estão sob o risco. Espera-se que estudos similares forneçam as bases para a adoção de políticas de prevenção e melhoria da atenção prestada a essas vítimas. 